\title{
The evolution of COPD species; or, something is changing for good in COPD
}

\author{
Joan B. Soriano $\mathbb{1}^{1,2}$ \\ Affiliations: ${ }^{1}$ Hospital Universitario de la Princesa, Universidad Autónoma de Madrid, Madrid, Spain. ${ }^{2}$ Centro \\ de Investigación en Red de Enfermedades Respiratorias (CIBERES), Instituto de Salud Carlos III (ISCIII),
} Madrid, Spain.

Correspondence: Joan B Soriano, Hospital Universitario de la Princesa, Diego de León 62, Neumología $6^{\text {a }}$ planta, 28030-Madrid, Spain. E-mail: jbsoriano2lagmail.com

@ERSpublications

COPD, both clinically and epidemiologically, is in constant evolution http://bit.ly/2X04qcn

Cite this article as: Soriano JB. The evolution of COPD species; or, something is changing for good in COPD. Eur Respir J 2019; 53: 1900762 [https://doi.org/10.1183/13993003.00762-2019].

At age 50 years, Charles Darwin (figure 1) published his theory of evolution, On the Origin of Species, in full, for his fellow scientists and for the public at large [1]. It was exactly 160 years ago, on a Thursday, 24 November 1859, priced at fifteen shillings. Three recent reports in the European Respiratory Journal on chronic obstructive pulmonary disease (COPD) have reminded us that not only species, but also diseases, experience evolution. At first glance, the three papers appear unconnected.

In this issue of the European Respiratory Journal, Bовнм et al. [2], describe the global awareness of COPD based on results from a popular internet search tool, Google Trends, that has proved of medical use in identifying and tracking epidemics in communicable and non-communicable diseases [3, 4]; within the 10 top causes of disease burden searched, it is no surprise that COPD ranked poorly, eighth according to the metrics they used, highlighting the low profile and the lack of awareness of COPD in the general population, in comparison to other deadly diseases. Of interest, they described a seasonal trend with a peak activity in November, likely related to the increased incidence of acute exacerbations during the winter period, but also reflecting the "noise" created by initiatives like the COPD Awareness Month and World COPD Day. This is good news.

In the second report, Topalovic et al. [5] employed an artificial intelligence (AI) algorithm in R language to 50 patients with different respiratory conditions, and demonstrated perfection (100\% agreement) in identifying an obstructive pattern of spirometry versus the American Thoracic Society/European Respiratory Society standards; this AI algorithm assigned a correct diagnosis to $82 \%$ of all patients, with $100 \%$ sensitivity for those with COPD. The latter greatly outperformed 120 pulmonologists from 16 hospitals across five European countries, who made correct diagnoses in only $24 \%$ to $62 \%$ of patients. Importantly, this AI algorithm, that reads lung function data (absolute values, percent predicted of normal reference values and $\mathrm{z}$-scores) combined with patient characteristics (age, pack-years, sex and body mass index) in $0.2 \mathrm{~s}$, is a very welcome revolution, as interpretation of spirometry was considered a bottleneck [6] in the global effort to reduce COPD underdiagnosis [7]. This too is very good news.

Finally, Celli et al. [8] explored, in the SUMMIT trial [9], the potential impact of the geographical origin of trial participants (not ethnic origin) on their response to the inhaled combination of the steroid fluticasone furoate $100 \mu \mathrm{g}$, and the long-acting beta-agonist (LABA) vilanterol $25 \mu \mathrm{g}$. They found a much higher (double!) response to treatment, measured by lung function decline, in Asian COPD patients from the following countries: China, Indonesia, India, Japan, Korea, Malaysia, Philippines, Taiwan, Thailand 


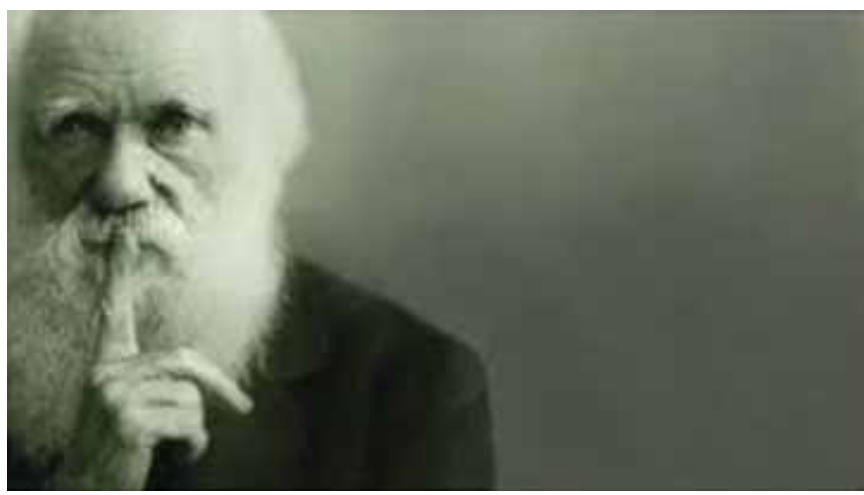

and Vietnam. This finding from SUMMIT had been previously observed in a randomised controlled trial of tiotropium in Chinese COPD patients [10]. Both observations are of interest due to the paucity of data regarding this issue. Any explanatory hypotheses are merely speculative; one possibility is that there may be "undertreatment" of COPD in these countries, and thus inhaled corticosteroid/LABA combination may demonstrate greater efficacy than in North America and Europe, where most COPD patients now receive a long-acting muscarinic antagonist or, at the very least, short-acting bronchodilator regularly. But the authors rightly note the relevance of this finding, because regional differences in response to therapy should be taken into account when comparing effects of therapeutic agents in different areas of the world.

The full title of Darwin's 490-page book was On the Origin of Species by Means of Natural Selection, or the Preservation of Favoured Races in the Struggle for Life. Apart from universally high rates of underdiagnosis [7], we have incontrovertible population evidence that the only constant thing in COPD and its determinants is change. COPD changes by place, in time, by gender, in the way we measure it, across phenotypes, and now also, in response to treatment. By applying Darwinian terminology, in all likelihood the COPD of the 21st century is different from the one seen in the 20th century, also called the cigarette century [11]. COPD is seen not only in males, smokers, and those who are older than 65 years. $A u$ contraire, COPD is rejuvenating, and can be detected from 3 to 95 years, and beyond [12]; it is feminising (figure 2), with female trends catching up with their male counterparts; it is growing in number due to population growth, global ageing and cumulative exposure to risk factors, to at least 174 million patients
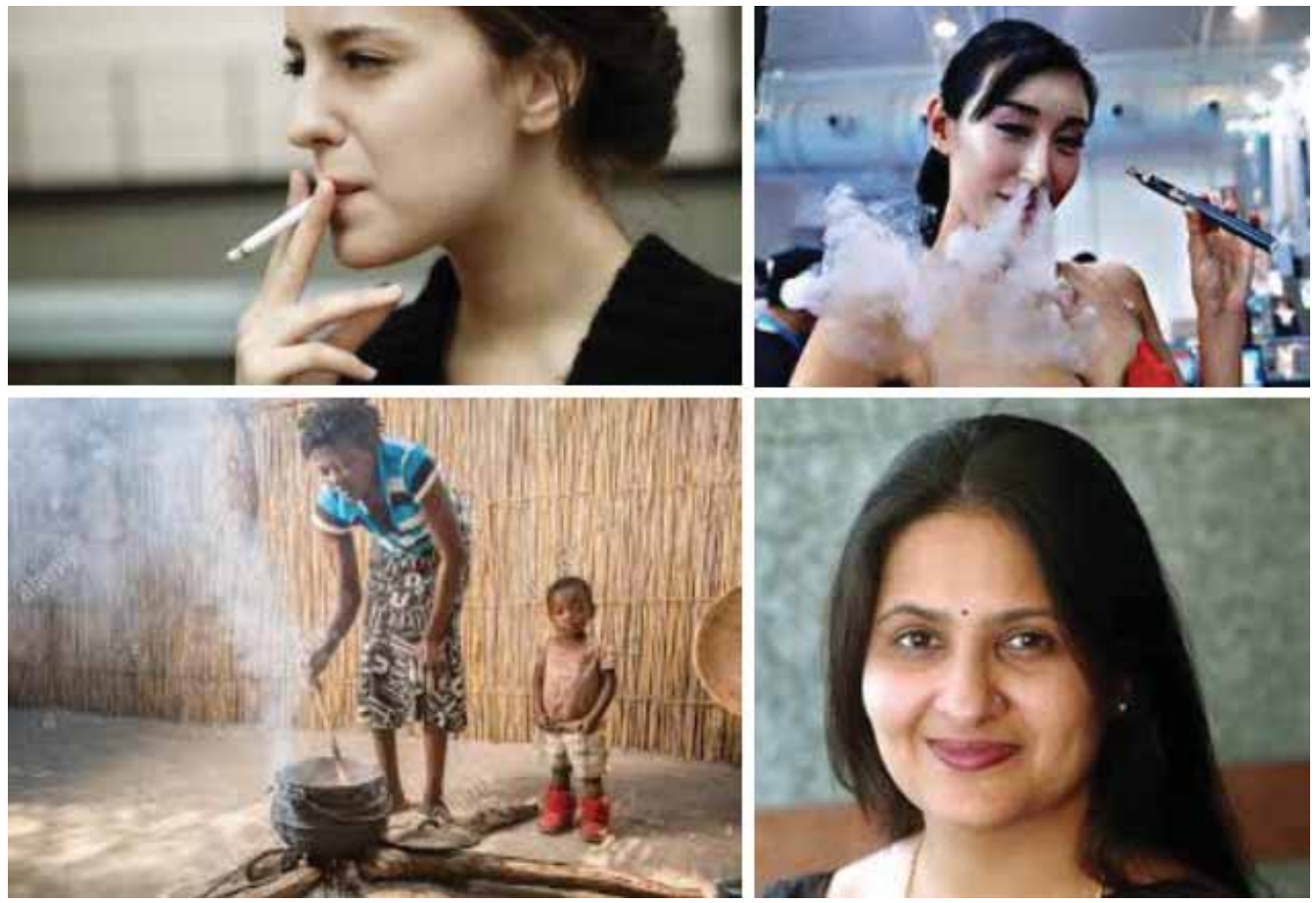

FIGURE 2 The changing face of chronic obstructive pulmonary disease. 
worldwide [13]; yet, epidemic outbreaks still occur in COPD [14]. By a sort of "artificial selection", antibiotic treatment is reducing the frequency of the blue bloater chronic bronchitis phenotype, but also global trends in overweight/obesity and home oxygen therapy appear to be reducing the pink puffer emphysema phenotype. Last, but indeed not least, COPD mortality trends in nearly all countries are falling, and by 2040 more people will die with rather than from COPD, becoming the paradigm of multimorbidity [15].

However, the new forms of smoking, with heat-not-burn tobacco, and vaping, will surely impact prevalent and new cases of COPD $[16,17]$. There is only one prescription needed to measure the burden of all these forms of COPD patients [18], and successfully overcoming their many challenges: monitoring trends by shoe-leather epidemiology [19], complemented by Big Data and other new technologies [20], such as AI. Implementation of tools like those described from Topalovic et al. [5] will be a tremendous help.

All in all, the future in COPD is bright; some have even called for entering a golden age of COPD research with the multi-omics revolution, to enable our patients to live longer and live better [21]. We should be ready to adapt to this new environment, to give to individuals and populations an effective response, for the preservation of the fittest COPD species in their struggle for breath...

Conflict of interest: J.B. Soriano participated in speaking activities, advisory committees and consultancies during the period 2014-2019 sponsored by: Almirall, AstraZeneca, Boehringer Ingelheim, CHEST, Chiesi, ERS, GEBRO, Grifols, GSK, Linde, Lipopharma, Mundipharma, Novartis, Pfizer, RiRL, Rovi, Sandoz, SEPAR and Takeda. J.B. Soriano declares not receiving ever, directly or indirectly, funding from the tobacco industry or its affiliates.

Support statement: This work was supported by Horizon 2020 HCO 2015 grant agreement number 681040 TackSHS. Funding information for this article has been deposited with the Crossref Funder Registry.

\section{References}

1 Darwin C. On the Origin of Species by Means of Natural Selection, or the Preservation of Favoured Races in the Struggle for Life. London, John Murray, 1859.

2 Boehm A, Pizzini A, Sonnweber T, et al. Assessing global COPD awareness with Google Trends. Eur Respir J 2019; 53: 1900351.

3 Carneiro HA, Mylonakis E. Google trends: a web-based tool for real-time surveillance of disease outbreaks. Clin Infect Dis 2009; 49: 1557-1564.

4 Schootman M, Toor A, Cavazos-Rehg P, et al. The utility of Google Trends data to examine interest in cancer screening. BMJ Open 2015; 5: e006678.

5 Topalovic M, Das N, Burgel PR, et al. Artificial intelligence outperforms pulmonologists in the interpretation of pulmonary function tests. Eur Respir J 2019; 53: 1801660.

6 Soriano JB, Zielinski J, Price D. Screening for and early detection of chronic obstructive pulmonary disease. Lancet 2009; 374: 721-732.

7 Lamprecht B, Soriano JB, Studnicka M, et al. Determinants of underdiagnosis of COPD in national and international surveys. Chest 2015; 148: 971-985.

8 Celli BR, Anderson JA, Brook RD, et al. Regional differences in rate of FEV1 decline in COPD: lessons from SUMMIT. Eur Respir J 2019; 53: 1900278.

9 Vestbo J, Anderson JA, Brook RD, et al. Fluticasone furoate and vilanterol and survival in chronic obstructive pulmonary disease with heightened cardiovascular risk (SUMMIT): a double-blind randomised controlled trial. Lancet 2016; 387: 1817-1826.

10 Zhou Y, Zhong NS, Li X, et al. Tiotropium in early-stage chronic obstructive pulmonary disease. N Engl J Med 2017; 377: 923-935.

11 Brandt AM. The Cigarette Century: The Rise, Fall, and Deadly Persistence of the Product That Defined America. New York, Basic Books, 2009.

12 Quanjer PH, Stanojevic S, Cole TJ, et al. Multi-ethnic reference values for spirometry for the 3-95-yr age range: the global lung function 2012 equations. Eur Respir J 2012; 40: 1324-1343.

13 GBD 2015 Chronic Respiratory Disease Collaborators. Global, regional, and national deaths, prevalence, disability-adjusted life years, and years lived with disability for chronic obstructive pulmonary disease and asthma, 1990-2015: a systematic analysis for the Global Burden of Disease Study 2015. Lancet Respir Med 2017; 5: 691-706.

14 Sun Y, Sin DD. Crisis of COPD in China: the future is now. Lancet Respir Med 2018; 6: 404-405.

15 Foreman KJ, Marquez N, Dolgert A, et al. Forecasting life expectancy, years of life lost, and all-cause and cause-specific mortality for 250 causes of death: reference and alternative scenarios for 2016-40 for 195 countries and territories. Lancet 2018; 392: 2052-2090.

16 Bowler RP, Hansel NN, Jacobson S, et al. Electronic cigarette use in US adults at risk for or with COPD: analysis from two observational cohorts. J Gen Intern Med 2017; 32: 1315-1322.

17 TackSHS. Project Summary. Tackling Secondhand Tobacco Smoke and E-cigarette Emissions: Exposure Assessment, Novel Interventions, Impact on Lung Diseases and Economic Burden in Diverse European Populations. http://tackshs.eu Date last accessed: April 8, 2019.

18 Almagro P, Soriano JB. Underdiagnosis in COPD: a battle worth fighting. Lancet Respir Med 2017; 5: 367-368.

19 Koo D, Thacker SB. In Snow's footsteps: commentary on shoe-leather and applied epidemiology. Am J Epidemiol 2010; 172: 737-739.

20 Tong SY. Genomic polish for shoe-leather epidemiology. Nat Rev Microbiol 2013; 11: 8 .

21 Sin DD, King GG. COPD: lessons learned, forging a fantastic future. Respirology 2017; 22: 632-633. 